ISSN No. 0974-035X

An Indexed, Refereed \& Peer Reviewed Journal of Higher Education

Towards Excellence

UGC-HUMAN RESOURCE DEVELOPMENT CENTRE,

GUJARAT UNIVERSITY, AHMEDABAD, INDIA

\title{
EDUCATION IN 21ST CENTURY, A CHALLENGE
}

\section{Mr. Digvijaysinh G. Gohil}

\section{INTRODUCTION}

We are in the 21 st century and it is time we take stock of what we have achieved in the field of education, what have been our failures and whether we need to continue in the same direction into this century or do things differently. In considering this question I would like to explore the situation globally and not with reference to any particular nation; also I would like to give a wide meaning to that word education, to cover the entire process of bringing up the next generation of children into adulthood and not limit it to only what transpires in a classroom in the school. A child is educated by the entire environment in which it grows, and that environment is determined equally by the parents, the teachers and the society around him/her. All this and more determines the kind of individual we produce, which in turn determines the kind of society we live in.

It is important to bear in mind the relationship of the individual to society. If we produce individuals who are self-centred, aggressive, ambitious, greedy and competitive, one cannot organize them into a society that is non-violent, peaceful, co-operative and harmonious. If we organize them into a communist society we shall have the violence and domination that we have seen in communist societies. It is not possible to bring a fundamental transformation in society unless the individual is transformed. Education is therefore the main engine of social transformation, since it determines the kind of individual we are producing. Governments, legislatures and the law enforcement agencies are only organizations to control the individual, they do not transform him. Therefore, true social change is the major responsibility of education, not merely the production of trained personnel. The test of right education today is whether it is producing good planetary citizens. 


\section{Digvijaysinh Gohil / Page 264-273}

The way we live has changed drastically over the last century and that change can be traced to what we have achieved in the field of education. At the beginning of the 20th century human society, all over the world, was beset with tremendous problems of natural disasters, famines, epidemics, primitive transportation, inefficient communication, lack of health care and poor agriculture. Our system of education has helped us to change all that, to develop all the knowledge and the power that was necessary to make the transition to the modern society in which we live today. The great strides that we have made in this century in the field of engineering, medicine, agriculture, transport, telecommunications, and power are all a direct consequence of our achievements in education. If so, then we should continue in the same direction. If not, then we must seriously consider whether we need an altogether different vision of education for the 21 st century.

\section{MAJOR CHALLENGES OF TODAY'S WORLD}

\section{i) Groupism/division :}

Perhaps the greatest problem we are facing today is the fact that human beings are divided into groups----racial groups, national groups, religious groups, linguistic groups, economic groups, political groups, professional groups ---- and each individual identifies with his or her own group, feels rivalry with other groups and cares only for the security and progress of a particular group. It is responsible for most of the violence that we see in the form of wars, terrorism, rioting and militancy. This is a malady that afflicts the most progressive and highly educated people as well as the most backward and illiterate people in the world today. The individual identifies with a particular family, country, religion and culture in which he/she is born. He/she is taught to feel proud of it and defend its ways. He/she feels secure in identifying with his or her group but this identification is in actual fact creating the greatest insecurity in the world today.

\section{ii) The power unleashed by science and technology :}

Human beings have lived with wars and rivalry for thousands of years but we cannot afford it any more due to the tremendous power that science and technology have placed in our hands. Our hatred of each other could only manifest in the killing of a few individuals when we lived with bows and arrows, spears and knives. Today, with our atomic and nuclear bombs we can decimate a whole nation in a matter of minutes and no war is a local war any more. This has 


\section{Digvijaysinh Gohil / Page 264-273}

greatly enhanced the urgency of the problem since mankind is in danger of annihilating itself in a nuclear war. We cannot therefore afford to postpone the solution to this problem. Human history has been a history of wars and if we do not learn now, we shall soon be fighting our last war.

\section{iii) The environmental catastrophes :}

Another major problem we are facing today are the environmental catastrophes about which we are constantly reading in our newspapers and magazines :depletion of the ozone layer, global warming industrial pollution, deforestation, soil-erosion, nuclear fall-outs and overpopulation. The root cause of most of these is the attitude we have developed towards nature in the course of this century, treating it as a resource meant to be exploited for our benefit. In the last one century our attitude has changed surreptitiously and unless this paradigm shift is undone we are going to face more and more environmental catastrophes. We may have better computers and faster planes but we will not have fresh air to breathe and new diseases caused by the disequilibrium will make life not worth living.

\section{iv) Dictatorships :}

Another great problem facing mankind is the fact that most of the governments in the world, especially in the third world countries, are still dictatorships --- military dictatorships, communist dictatorships, religious dictatorships and dictatorships in the garb of democracy. There are very few countries where there is real democracy and freedom of expression, political freedom, freedom to grow, freedom to question, to think, to write what you believe in. Dictatorships stifle dissent, they tell people what to think, what to do and what not to do. The greatest crimes of this century have been perpetrated under dictatorships.

The very basis of dictatorship is the exploitation of the weak by the powerful. So long as we believe that power is meant for exploiting the weak, we still accept that might is right, which is the law of the jungle. Unless mankind can change its relationship with power, power will continue to be used for destruction and domination. So education must concern itself with bringing about the right use of power, which is the true spirit of democracy. We object to dictatorship when it is at the level of the government but all dictatorship is evil, whether it is in an organization, a business or in the family. Therefore the spirit of democracy needs to be inculcated in every individual if the problems of dictatorship are to disappear.

\section{v) The breakdown of the family:}




\section{Digvijaysinh Gohil / Page 264-273}

The institution of marriage and family was set up partly to regulate sexual behaviour but more importantly, to ensure that we are able to discharge our responsibilities towards the next generation. The human child needs to be looked after, protected and helped to learn not for a few days or a few months, as is the case with other mammals, but for a period of 20 years, since there is a whole new dimension of mental, emotional and spiritual growth involved. Today, cooperation between man and woman is breaking down in modern society and the incidence of divorce is now as high as $60 \%$ in some affluent societies. The worst sufferers of this breakdown in co-operation are the children and consequently juvenile crime is on the rise. Obviously, we are not approaching life rightly and we need to rethink where we have gone wrong.

\section{vi) The inertia in society:}

Last but not the least, is the great problem that society tends to replicate itself. Prejudices and illusions tend to continue from one generation to the next and so do the problems associated with them. The prejudices of the elders continue in the young and so does the problem of animosity. It is the same with the Catholics and the Protestants or the Hindus and the Muslims. This animosity will never end so long as we educate the children to obey and conform to what their elders are saying. We must therefore create an inquiring mind, which questions what it is told, is aware that it has many prejudices that need to be examined and dropped and is willing to undertake this task of discovering for itself what is true. But it is essential to encourage and respect dissent if we are not to create a static society that is inflexibly caught in a fossilized groove. There is too much inertia in society today and the only way to change it is to create a mind that is inquiring not only into scientific questions, but also into social, moral and religious questions. In other words a mind that is intelligent about the whole of life and not merely one aspect of it.

\section{THE ROLE OF EDUCATION}

If we are facing so many problems at the end of this century of stupendous progress, then we must stop and ask ourselves what it is that we have done wrong? Why are we facing so many serious problems though we have amassed so much knowledge, created so much power/ability and become so 'intelligent'. Do we need better controls or do we need to change direction ? Will more of the same kind of education as we have been imparting solve these problems? Do we need still better computers, still faster airplanes, still more goods, yet more knowledge and efficiency and will that solve the problems we have discussed above ? If not, then should we not 


\section{Digvijaysinh Gohil / Page 264-273}

re-examine our priorities in education and question the very vision with which we have been working so far?

\section{The present vision of education}

What is our vision of education today ? What kind of human being are we aiming to produce? The aims may vary a little from country to country but essentially, all over the world, education is aiming to produce a human being who is intelligent, knowledgeable, hard-working, efficient disciplined, smart, successful and hopefully a leader in his field of endeavour. If one may most humbly point out, Adolf Hitler had all these qualities and yet most people regard him as the most evil person of this century. The only thing he lacked was love and compassion. So what is there in our present day education to prevent the creation of a Hitler or of little Hitlers for that matter ? The holocaust, perhaps the greatest crime of this century, was perpetrated in a country that had the best of science, art, music and culture of the kind we are aiming to inculcate through education today. So what is there in present-day education to prevent the recurrence of the holocaust? Indeed, we are perhaps at the brink of a still larger holocaust in which the whole of mankind may be eliminated from the face of the earth in a nuclear war. Present day education is basically developing greater and greater power; but both God and the Devil (as conceived by us) are infinitely powerful. Are we ensuring that the power we produce will be used in godly ways and not in devilish ways? If not, then it is irresponsible to generate power.

The major challenges facing mankind today are not due to a lack of education nor created by the illiterate villagers in Asia or Africa, they are created by highly educated and professional minds-----lawyers, business administrators, scientists, economists, military commanders, diplomats etc. So we need to look at the kind of education we are imparting and not the quantity. It is this lop-sided development of the individual that is responsible for all the problems we are facing today. As an educationalist we must accept that when we impart knowledge it is also our responsibility to impart or awaken the wisdom to employ it rightly. Our present day education has not paid serious attention to that responsibility.

\section{A DIFFERENT VISION OF EDUCATION}

Keeping in mind what we have said so far, how should we modify our vision of education for the 21 st Century? What values should we try to inculcate? The prescription 


\section{Digvijaysinh Gohil / Page 264-273}

would not be identical for all countries and different cultures may go about it in their own unique way, but the broad outlines can be stated as follows:

\section{i) Create a global mind, not a nationalistic one}

We are all citizens of one world and we share the earth as our common habitat. What affects one part of the world today is of concern to all of us. So we need to have a mind that feels for the whole world and not just for one country. We are part of one world, one humanity and if we can settle issues within a country through democratic means and adjudication, is it not right to do that also between nations ? If we have a global mind that really did not believe in "might is right" there would be no armies and no wars. That is the future we must realize for the $21 \mathrm{st}$ century. We may work for local problems but it is important to do so with a global understanding.

\section{ii) Emphasise human development, not only economic}

Education must not regard children as raw material for achieving the economic progress of the nation. It must concern itself primarily with the development of all aspects of a human being --physical, intellectual, emotional and spiritual ---- so that he or she lives creatively and happily as a part of the whole. Human beings may differ in their abilities but they are not unequal, neither superior or inferior. They must be respected irrespective of their abilities. Goodness must be valued above efficiency.

\section{iii) Encourage inquiry, not conformity}

It may be inconvenient for the adults but it is important that children grow up with questions, rather than answers. At each age the questions will naturally be different but the ability to inquire and to learn for oneself is more important than to obey and follow unquestioningly what one is told to do. It follows that there must be no fear in our relationship with the child since fear kills inquiry and initiative. The child must be free to make mistakes and learn for itself without the constant fear of being rebuked by an adult. Such a mind is rational, flexible and not dogmatic, open to change and not irrationally attached to an opinion or belief. This implies the absence of all propaganda for any belief, including nationalism. "Our country is the best country, our culture is the best culture" is not true --- it is propaganda, which divides people.

\section{iv) Cultivate co-operation, not competition}

The present emphasis in the world on individual achievement for name and fame is 


\section{Digvijaysinh Gohil / Page 264-273}

irrational and egotistic. We are all inter-related and inter-dependent and little that is really meaningful can be achieved alone and in isolation. Team work and the ability to work harmoniously with others is more important than individual achievement. Co-operation is the essence of democracy. One works not for personal gain or reward but for the welfare of the whole community, with love instead of arrogance. The sense of competition that we are encouraging in children today leads to envy, jealousy and rivalry. It sows the seeds of division between human beings and destroys love and friendship. Therefore, it is evil. The importance we have given to winning gold medals in world-cup matches and Olympics is based on propaganda and illusion. Does it really matter which human being can jump one millimeter higher than all the others? We are not asking the right question when we ask, "Who won ?". The more important question is, "Did they enjoy the game ?".

\section{v) Create a learning mind instead of an acquisitive mind}

The awakening of intelligence is more important than the cultivation of memory, both in life and in academics. If we give information to the child we add to his knowledge but intelligence is the ability to learn for oneself. What can be taught is limited but learning is endless. The greatest things in life are those that cannot be taught but they can be learnt. The feeling of love, respect, beauty, and friendship, cannot be taught but like sensitivity, it can be awakened and this is an essential part of intelligence. The ability to discern for oneself what is true and what is false is also intelligence. It is important to create a mind that neither accepts nor rejects an opinion or a view too readily, but stays with the question, "Is it true ?".

\section{vi) Create a mind that is both scientific and religious in the true sense}

Unfortunately we have divided the scientific quest from the religious quest of mankind and concentrated only on the former in the educational process. In fact they are two complimentary quests, one for the discovery of the order that manifests itself in the outer world of matter, energy, space and time and the other for discovering order in the inner world of our consciousness. By mistakenly equating religion with belief we have created an antagonism between science and religion. Actually they are both quests for truth into two complimentary aspects of a single reality. One that is only religious (in the narrow sense) can be overly emotional, sentimental, superstitious and therefore neurotic. We must therefore aim at creating a mind that is both scientific and religious at the same time ---- one that is inquiring, precise, rational and skeptical but at the same time has a sense of beauty, wonder, aesthetics, sensitivity, 


\section{Digvijaysinh Gohil / Page 264-273}

humility, and an awareness of the limitations of the intellect. Understanding oneself (selfknowledge) is as important as understanding the world. Without a deep understanding of our relationship with nature, with ideas, with fellow human beings, with society, and a deep respect for all life one is not really educated.

\section{vii) The art of living}

Education must concern itself with the art of living creatively, which is much vaster than the specific arts of painting, music or dance which we teach at present. We have equated the quality of life with the standard of living and we measure this in terms of the Gross National Product or the per-capita income of people.

When we educate not for economic development but for human development we must concern ourselves with the happiness of the individual as whole, in which physical well- being and comfort are a small but necessary part. Far more important is the ability to work with joy, without comparing oneself with others. If one is insensitive, there is constant boredom and to escape from it a constant pursuit of pleasure. When we teach children to work for a reward and not for the joy of working, we teach them to separate work from pleasure. Such a mind is energized only when there is a reward, otherwise it lives in a state of boredom. The art of living consists in enjoying everything one does, irrespective of the results it offers. It cannot be learnt like a formula. It is a by-product of one's understanding of life and of oneself. Therefore we must help students to come upon such understanding.

\section{DIFFICULTIES OF IMPARTING SUCH EDUCATION}

There are several difficulties in actually imparting such an education. The greatest difficulty is that we have ourselves not received the right kind of education. Therefore we must not mechanically repeat what we know. We need to question our methods and not merely repeat what our teachers and parents did. It requires us to be original, intelligent, creative and not merely asserting ourselves. Our minds are conditioned into the old system, the old vision, therefore we are ourselves obstacles in the way of the new! One has to be acutely aware of this fact and therefore not just teach but also learn to break from the past.

In the new vision of education we are not only taking the responsibility to impart information and skills but also to awaken sensitivity and creativity in the child. There is no set method for doing this. These are things that cannot be decided, practised and achieved. Yet, they get awakened in the child if there is the right atmosphere in the school and the home. It is 


\section{Digvijaysinh Gohil / Page 264-273}

our responsibility to create the atmosphere of working co-operatively, with joy and friendship, working hard but without personal ambition or any sense of rivalry, an atmosphere of openness, of questioning, of inquiry, and the joy of learning together. A child learns from what he sees actually happening around him or her, not from what we speak in the classroom. If it finds that we say one thing and do another, it will also learn to do precisely that. The child imbibes the values he/she sees, not those that are talked about. Intellectually we adults may know more than the child but in the larger issues of life we face the same problems, the same difficulties as the child - problems of boredom, worry, fear, habit, conflict, desire, frustration and violence.

Therefore we need to learn along with the child, not merely teach. It demands great honesty, humility, sensitivity and patience. That is our difficulty ---- to be an educator who is willing to accept that challenge and not seek an easy way out. There isn't one. The deeper truths come to a reflective mind as insights that cannot be taught by another. One cannot do anything to create insights but one must not block them with an ambitious and overly active mind which has no time to stand and stare.

\section{CONCLUSION:}

Mankind is caught in a great illusion. It thinks it can solve its problems through legislation, through political and social reform, through scientific and technological progress, through greater knowledge, greater wealth, greater power and greater control. It may solve some problems with all this, but those are all trivial problems and temporary cures. By these methods we shall go on creating new problems on the one hand and trying to solve them on the other to maintain the illusion of progress. The famous humorist Ogden Nash wrote, "Progress was all right once, but it went on too long" ! We need to consider that remark seriously. If we human beings do no transform inwardly, we shall soon join the list of those unfortunate creatures that lived a million years or so and then became extinct for they could not adapt themselves. It is not certain yet if evolution of man from the ape was really a step in the direction of survival. Only time will tell. Survival requires not the intelligence of 'progress' but the ability to co-operate and love each other and to live in harmony with nature. The ant has survived longer than man. What we need now is not more ability and more efficiency, but greater cohesion, greater compassion, greater capacity to share and work together.

Education in the 21st Century must therefore concern itself not with greater 'progress' but with the inner transformation of the human consciousness. It is not that this has not been pointed out 


\section{Digvijaysinh Gohil / Page 264-273}

before. The Buddha, Socrates, Christ and innumerable other sages in all cultures have pointed this out long ago. Till now we have ignored what they have said but still managed to survive somehow. We cannot afford to do that anymore, for we are inexorably heading towards a nuclear holocaust which will make survival not worth it, if not impossible. Therefore the issue has acquired urgency for mankind which was not there before.

In presenting the vision of right education for the 21 st Century I have drawn heavily from the life and work of Madam Montessori (1) and of J. Krishnamurti (2), both of whom have emphasised the need for educating the whole human being and not merely the intellect. Out of this vision, Madam Montessori developed certain methods and techniques for use with small children since she took upon herself that task. But the techniques and materials she developed have meaning only when the teacher shares her vision of life; otherwise the teacher may use those very materials to inculcate a sense of competition and achievement among the children ! A school is not a Montessori school just because it adopts the use of those techniques and materials. The technique does not create the vision; it is the vision that creates the technique. It is important to come upon that vision of life and to actually live that way throughout life. Unless education helps the student to do that it has very little significance. It means we must be students all our life, living with deep and fundamental questions. One such question is, what does it mean for a human being to live in harmony with the cosmic order? The twenty-first century demands a total change in our outlook on life and our vision of education.

\section{References}

1. Standing, E.M..Maria Montessori - her life and work. Mentor-Omega books, London. 1957.

2. Krishnamurti, J. Education and the significance of life. Gollancz, London. 1955.

\section{Digvijaysinh G. Gohil}

\section{Shree Sahjanand Arts and Commerce College}

Ahmedabad, Gujarat, India.

E-mail - dgohil75@gmail.com 